\title{
INVENTARISASI JAMUR DAN BAKTERI YANG BERASOSIASI DENGAN BENIH PADI (Oryza Sativa L. ) DI LAMPUNG
}

\author{
Yuktika, M. Nurdin \& Suskandini Ratih D. \\ Jurusan Agroteknologi, Fakultas Pertanian Universitas Lampung \\ J1. Prof. Soemantri Brodjonegoro, No. 1, Bandar Lampung 35145 \\ E-mail: Yuktikatiki90@yahoo.com
}

\begin{abstract}
ABSTRAK
Penelitian ini bertujuan untuk mengetahui genus jamur dan bakteri terbawa benih padi yang berasal dari Lampung. Pengambilan sampel benih padi menggunakan sampel acak dengan gulungan kertas yaitu Lampung Utara, Lampung Selatan, Lampung Tengah dan Lampung Timur. Petani yang memiliki produksi padi lebih unggul dan areal tanaman padi yang terluas dijadikan sebagai tempat pengambilan sampel benih padi. Benih-benih diuji dengan metode pemeriksaan benih kering dan metode inkubasi pada media Potato Sucrose Agar. Benih yang telah direndam selama 2 menit dalam aquades dikeringkan dengan menggunakan kertas tisu. Kemudian benih tersebut diinkubasi didalam media PSA selama 3-5 hari. Setiap cawan petri berisi 15 butir benih padi. Pada saat inkubasi diberi perlakuan gelap dan terang, masing-masing selama 12 jam secara bergantian, perlakuan ini ditujukan untuk merangsang sporulasi jamur terbawa benih. Pengamatan dilakukan pada hari ketiga dengan membuat preparat untuk diamati dibawah mikroskop majemuk. Hasil penelitian menunjukkan adanya jamur yang berasosiasi dengan benih padi yang berasal dari empat kabupaten. Lima genus jamur yang ditemukan secara berurutan dari yang paling sering muncul sampai yang jarang muncul adalah Aspergillus (37,9\%), Mucor (33,6\%), Trichoderma (6,3\%), Penicillium (3,9 $\%)$ dan Rhizopus $(0,6 \%)$.
\end{abstract}

Kata kunci : Bakteri, benih padi, inventarisasi, jamur.

\section{PENDAHULUAN}

Dalam rangka mewujudkan ketahanan pangan nasional di masa yang akan datang dan mencukupi kebutuhan pangan Indonesia memerlukan peningkatan produksi padi melalui penyiapan benih bermutu dan tepat waktu. Benih merupakan salah satu faktor yang sangat menentukan keberhasilan budidaya tanaman. Perannya tidak dapat digantikan oleh faktor lain karena benih sebagai bahan tanaman dan sebagai pembawa potensi genetik terutama untuk varietas-varietas unggul (Balai Besar Penelitian Tanaman Padi, 2008).

Benih merupakan produk komersil dengan nilai jual tinggi. Benih juga merupakan salah satu alat penularan patogen tanaman. Benih bermutu adalah benih yang baik yang menjamin pertanaman bagus dan hasil panen tinggi. Saat ini benih bermutu dicerminkan oleh keseragaman biji, daya tumbuh, dan tingkat kemurnian yang tinggi. Syarat benih bermutu harus memiliki enam kriteria yaitu murni dan diketahui nama varietasnya, daya tumbuh tinggi (minimal 80\%), vigornya baik, biji sehat yang dipanen dari tanaman tua yang sehat, tidak terinfeksi oleh hama dan patogen (jamur dan bakteri), bersih (tidak tercampur varietas lain, biji rerumputan, dan kotoran lainnya).

Benih dapat dikatakan sehat apabila benih tersebut telah memenuhi persyaratan fisiologis, genetis, serta tidak mengandung inokulum patogen yang terdiri atas bakteri dan jamur baik secara eksternal maupun internal dalam struktur benih (Direktorat Jenderal Tanaman Pangan dan Hortikultura, 1999). Menurut Nurdin (2003), benih padi yang diinkubasi dengan menggunakan metode kertas hisap menunjukkan bahwa frekuensi mikroorganisme tertinggi adalah Alternaria baik menggunakan metode kertas hisap (90\%) maupun metode PDA (93,33\%), sedangkan mikroorganisme urutan berikutnya pada kedua metode itu berlainan.

Pada metode kertas hisap ditemukan bakteri (60\%), Fusarium (50\%), Curvularia $(36,66 \%)$ dan Aspergillus (10\%), sedangkan metode PDA ditemukan Fusarium (8,66\%), Aspergillus (26,66\%), Penicillium (26,66\%), Curvularia (16,66\%), Rhizopus (13,33\%), Mucor (3,33\%) dan bakteri (30\%). 


\section{BAHAN DAN METODE}

Pengambilan sampel benih padi menggunakan sampel acak dengan gulungan kertas. Setelah dilakukan sampel acak maka diperoleh 4 kabupaten yaitu Lampung Utara, Lampung Selatan, Lampung Tengah dan Lampung Timur. Dari masing-masing kecamatan diambil 1 kecamatan setelah dilakukan sampel acak yaitu kecamatan Way Jepara Lampung Timur, kecamatan Abung Surakarta Lampung Utara, kecamatan Punggur Lampung Tengah dan kecamatan Jati Agung Lampung Selatan. Untuk tingkat desa dilakukan sampel acak dengan gulungan kertas sehingga diperoleh satu desa. Petani yang memiliki produksi padi lebih unggul dan areal tanaman padi yang terluas dijadikan sebagai tempat pengambilan sampel benih padi. Berdasarkan peraturan ISTA maka dari masing-masing sampel benih padi diambil 40 gram benih padi yang akan dibawa ke Laboratorium.

Menurut Nurdin (2003), pemeriksaan benih kering dilakukan untuk mengetahui keadaan benih padi yang akan digunakan dalam penelitian. Benih padi diperiksa dan diamati secara langsung. Pemeriksaan dilakukan dengan cara mengamati benih normal, kotoran pada benih dan benih rusak yaitu benih-benih padi yang retak, pecah, terserang hama dan terserang penyakit.

Nurdin (2003) juga mengemukakan bahwa pengujian ini lebih didasarkan pada pertumbuhan inokulum, dengan mengamati spora atau konidia yang diambil dari koloni jamur yang tumbuh pada benih setelah inkubasi. Untuk keperluan media digunakan Potato Sucrose Agar (PSA).

Benih yang telah direndam selama 2 menit dalam aquades dikeringkan dengan menggunakan kertas tisu. Kemudian benih tersebut disebar diatas media agar (PSA) dan diinkubasi selama 3-5 hari. Setiap cawan petri berisi 15 butir benih padi. Pada saat inkubasi diberi perlakuan gelap dan terang, masing-masing selama 12 jam secara bergantian, perlakuan ini ditujukan untuk merangsang sporulasi jamur terbawa benih.
Pengamatan dilakukan pada hari ketiga dengan membuat preparat untuk diamati dibawah mikroskop majemuk.

\section{HASIL DAN PEMBAHASAN}

Hasil pemeriksaan benih kering di empat kabupaten menunjukkan bahwa benih diperiksa secara kering sehingga tidak tercampur dengan kotoran-kotoran seperti sisa-sisa tanaman, gulma dan lain-lain, butir hampa dan butir rusak yang disajikan pada Tabel 1. Hasil pemeriksaan benih kering pada padi (Tabel 1) menunjukkan bahwa benih padi di Lampung Selatan diperoleh butir sehat $86,25 \%$, butir hampa $4,75 \%$, butir rusak $7,25 \%$ dan kotoran $1,75 \%$ yang berupa pasir dan batang jerami. Benih padi di Lampung Tengah diperoleh butir sehat $68,25 \%$, tidak ada butir rusak pada benih, butir hampa 30,5\% dan kotoran 1,25\%. Benih padi di Lampung Timur diperoleh butir sehat 87,5\%, butir rusak

$3,5 \%$, butir hampa $7,75 \%$ dan kotoran $1,25 \%$. Benih di Lampung Utara diperoleh butir sehat 86,5\%, butir rusak $1,75 \%$, butir hampa $10,5 \%$ dan kotoran $1,25 \%$ yang berupa batang jerami dan daun. Butir rusak yang diperoleh dari petani disebabkan benih-benih tersebut sudah mengalami penyimpanan meskipun adapula benih rusak yang terbawa dari lapang. Ciri-ciri butir rusak adalah kulit butir padi yang berubah warna, benih yang pecah, kulit mengelupas. Butir berwarna coklat muda atau tua, bintik-bintik hitam atau bercak putih kecoklatan. Kotoran benih meliputi benih tanaman lain, bagian dari benih serta bahan-bahan lain yang bukan bagian dari benih seperti batu, pasir, tanah, batang jerami dan daun. Butir hampa dapat disebabkan serangan jamur seperti Fusarium. Jamur Fusarium dapat menyerang bunga dan butir- butir, terutama yang masih muda (Semangun, 1993).

Hasil pengujian kesehatan benih dengan metode inkubasi pada media PSA menunjukkan bahwa jamur yang berasosiasi pada benih padi adalah Aspergillus,

Tabel 1. Kondisi benih padi yang berasal dari empat kabupaten

\begin{tabular}{ccccc}
\hline \multirow{2}{*}{ Wilayah } & \multicolumn{4}{c}{ Persentase } \\
\cline { 2 - 5 } & Butir hampa & Butir rusak & Butir sehat & Kotoran \\
\hline Lampung Selatan & 4,75 & 7,25 & 85,25 & 1,75 \\
Lampung Tengah & 30,50 & - & 68,25 & 1,25 \\
Lampung Timur & 7,75 & 3,50 & 87,5 & 1,25 \\
Lampung Utara & 10,5 & 1,75 & 86,5 & 1,25 \\
\hline
\end{tabular}

Keterangan : $(-)=$ Tidak ditemukan adanya jamur. 
Mucor, Penicillium, Rhizopus dan Trichoderma. Ratarata temuan jamur dan bakteri pada benih padi disajikan pada Tabel 2.

Hasil temuan jamur pada benih padi (Tabel 2) menunjukkan bahwa jamur yang dominan dari Lampung Selatan adalah genus Aspergillus (47,9 \%), Lampung Tengah adalah genus Mucor (26,6 \%), Lampung Timur adalah genus Mucor $(66,6 \%)$ dan Lampung Utara adalah genus Aspergillus (77,3 \%). Petani Lampung Selatan, Lampung Utara dan Lampung Timur menggunakan benih padi pada hasil panen sebelumnya untuk digunakan sebagai bibit dan cara penyimpanan benih padi yang kurang baik dapat mengakibatkan terjadinya respirasi, tumbuhnya jamur dan serangan serangga, binatang mengerat (seperti tikus) dan serangan kutu beras yang dapat menurunkan mutu padi. Sedangkan Lampung Tengah benih padi hasil panen di gudang tidak terserang jamur karena padi harus kering, kadar airnya bagus berkisar $14 \%$, pengemas karung plastik yang baik, ruang penyimpanan atau lingkungan bersih bebas dari debu, maupun kotoran, tidak ada serangan hama gudang baik berupa serangga, tikus, maupun burung, penerangan dan ventilasi yang cukup dan mudah dibersihkan. Penyimpanan beras ada 2 sistem yaitu sistem curah yaitu penyimpanan tanpa menggunakan kemasan dan sistem kemasan yaitu beras dikemas, misalnya dalam karung, kantong plastik kapasitas $10 \mathrm{~kg}, 25 \mathrm{~kg}, 50 \mathrm{~kg}$ baru disimpan dalam bentuk tumpukan. Dari keempat kabupaten jamur yang paling dominan adalah genus Aspergillus. Koloni genus Aspergillus berwarna hitam dan sangat dapat memanfaatkan nutrisi pada media tumbuh serta reproduksi dan pertumbuhannya lebih cepat sehingga dapat tumbuh dengan mudah di berbagai media. Koloni genus Mucor seperti kapas putih yang ditunjukkan pada Gambar 1.

Aspergillus merupakan fungi dari filum ascomycetes yang berfilamen, mempunyai hifa berseptat dan dapat ditemukan melimpah di alam dan genus Mucor memiliki sporangiofor panjang serta pendek dan bercabang-cabang yang ditunjukkan pada Gambar 2 . Genus Penicillium meiliki koloni berwarna biru. Konidiofor yang ujungnya bercabang-cabang seperti sapu, fialid berbentuk botol. Genus Penicillium bersifat saprofit dapat merusak hasil-hasil pertanian dalam penyimpanan yang disajikan pada Gambar 3 .

Genus Rhizopus memiliki koloni berwarna putih dan menjadi abu-abu dengan bertambahnya usia biakan. Rhizoid berwarna kecoklatan, sporangiofor tunggal atau berkelompok dan kolumela berbentuk bulat yang disajikan pada Gambar 4. Genus Trichoderma merupakan jamur tanah yang tersebar luas dan hampir dapat ditemui di lahan-lahan pertanian. Genus Trichoderma bersifat saprofit dan parasit pada jamur lain yang dapat menyerang dan mengambil nutrisi dari jamur lain. Genus Trichoderma berkembang biak secara aseksual dengan membentuk spora diujung fialida atau cabang dari hifa. Koloni genus Trichoderma berwarna hijau muda dan hijau tua. Hifa berbentuk pipih, bersekat dan bercabang-cabang membentuk anyaman yang disebut miselium. Miseliumnya dapat tumbuh dengan cepat dan dapat memproduksi berjuta-juta spora karena sifatnya yang memiliki daya kompetitif yang tinggi. Konidia berseptat yang disajikan pada Gambar 5 .

Jamur yang biasanya terbawa oleh benih padi dari lapangan antara lain Rhizopus, Fusarium, Aspergillus, Curvularia, Penicillium, Alternaria, dan Pyricularia.

Tabel 2. Rerata persentase perkecambahan benih dan frekuensi kemunculan jamur dan bakteri sampel benih padi yang berasal dari empat kabupaten

\begin{tabular}{|c|c|c|c|c|c|c|c|}
\hline \multirow[t]{3}{*}{ Wilayah } & \multicolumn{6}{|c|}{ Mikr oorganisme (\%) } & \multirow{3}{*}{$\begin{array}{c}\text { Rerata } \\
\text { Perkecambahan } \\
\text { Benih }\end{array}$} \\
\hline & \multicolumn{5}{|c|}{ Jamur } & \multirow{2}{*}{ Bakteri } & \\
\hline & $\overline{\text { Aspergillus }}$ & Mucor & Penicillium & Rhizopus & Tricoderma & & \\
\hline Lampung selatan & 47,9 & 37,3 & - & - & 1,3 & 22,6 & 66,6 \\
\hline Lampung tengah & 15,9 & 26,6 & 1,3 & 1,3 & 9,3 & 89,3 & 58,6 \\
\hline Lampung timur & 10,6 & 66,6 & 14,6 & - & 14,6 & 58,6 & 78,6 \\
\hline Lampung utara & 77,3 & 4 & - & 1,3 & - & 89,3 & 17,3 \\
\hline Jumlah & 151,7 & 134,5 & 15,9 & 2,6 & 25,2 & 259,8 & 221,1 \\
\hline Rerata & 37,9 & 33,6 & 3,9 & 0,6 & 6,3 & 64,9 & 55,2 \\
\hline
\end{tabular}

Keterangan : $(-)=$ Tidak ditemukan adanya jamur. 
(a)

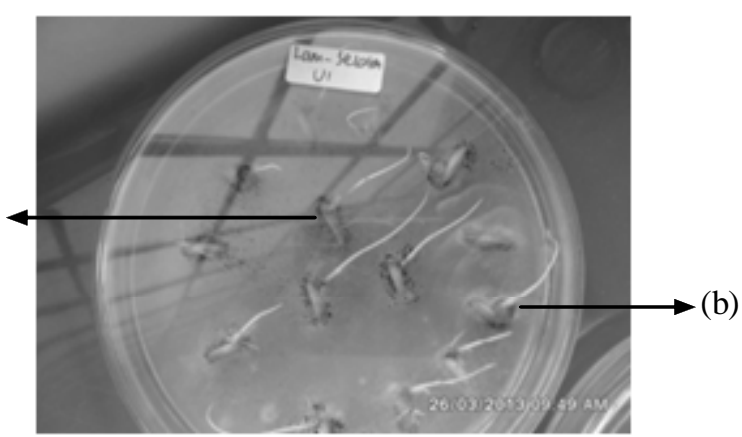

Gambar 1. Isolat genus Aspergillus dan genus Mucor secara makroskopis pada benih padi. (a) = Koloni genus Aspergillus berwarna hitam, (b) = Koloni genus Mucor seperti kapas putih.

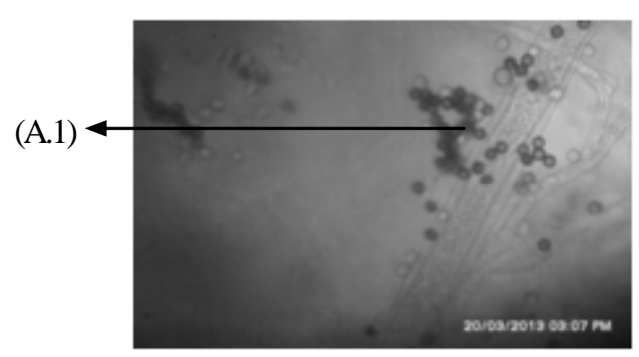

(A)

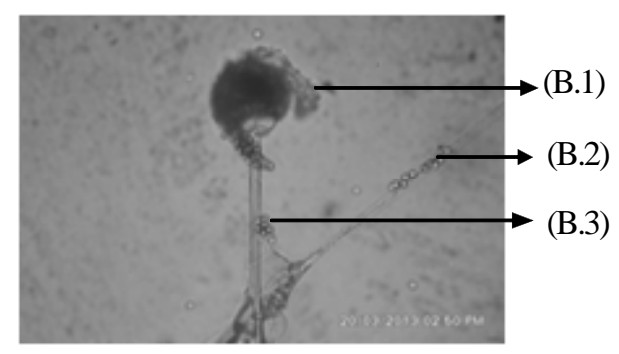

(B)

Gambar 2. (A) = Jamur genus Aspergillus secara mikroskopis pembesaran $400 \times$, (A.1) konidia. (B) = Jamur genus Mucor secara mikroskopis pembesaran $400 \times$, (B.1) sporangium, (B.2) Sporangiospora, (B.3) Sporangiofor.

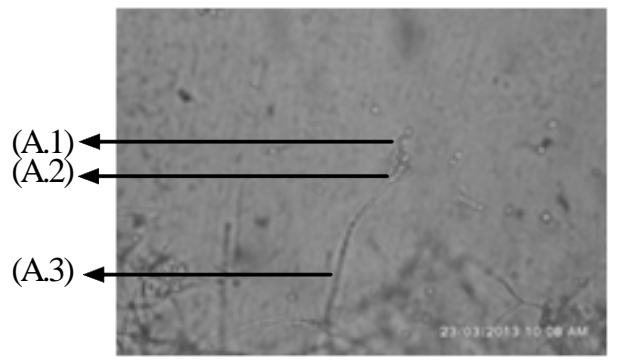

(A)

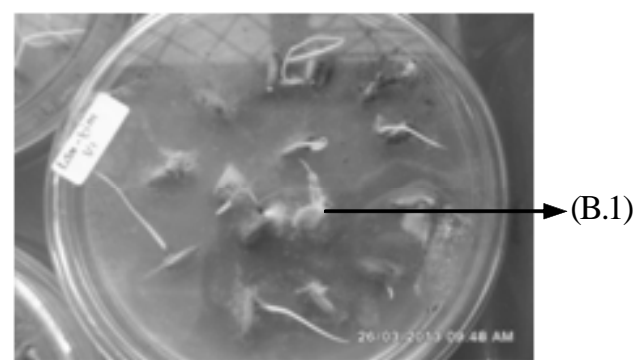

(B)

Gambar 3. Jamur genus Penicillium. (A) = secara mikroskopis pembesaran $400 \times$, (A.1) konidia, (A.2) metula, (A.3) konidiofor. (B) = secara makroskopis pada benih padi, (B.1) koloni genus Penicillium berwarna biru.

Terlebih lagi keberadaan jamur jenis Aspergillu., Penicillium dan Rhizopus meningkat selama penyimpanan benih (Masniawati, 2013). Meskipun genus Fusarium termasuk jamur lapangan namun genus Fusarium akan dapat melanjutkan kerusakan bahan benih dalam penyimpanan. Jamur yang berasosiasi dengan benih padi tidak hanya jamur yang terbawa dari lapang tetapi terdapat juga jamur yang terdapat dalam penyimpanan seperti jamur genus Aspergillus, genus Penicillium, genus Rhizopus dan genus Mucor.
Semuanya adalah jamur saprofit yang bukan terbawa dari lapang (Semangun, 1993). Hal ini disebabkan benih padi tersebut sudah melalui proses penyimpanan. Jamurjamur yang terbawa dari lapang akan berada dalam keadaan dorman selama benih disimpan (Justice dan Bass, 1994). Jamur dapat bertahan beberapa tahun selama dalam penyimpanan karena lingkungan yang mendukung untuk tumbuhnya jamur tersebut. Adanya jamur penyimpanan yang berasosiasi dengan benih padi mungkin karena pada tingkat petani benih yang disimpan 


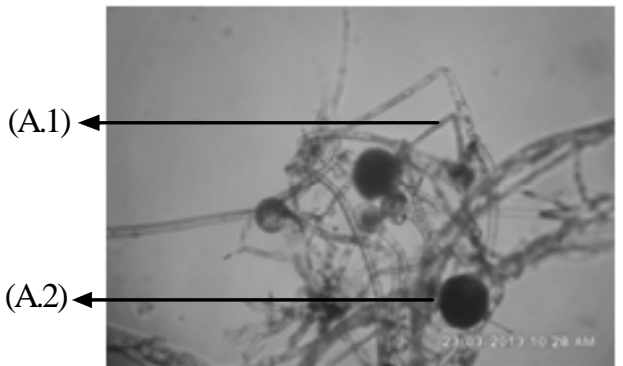

(A)

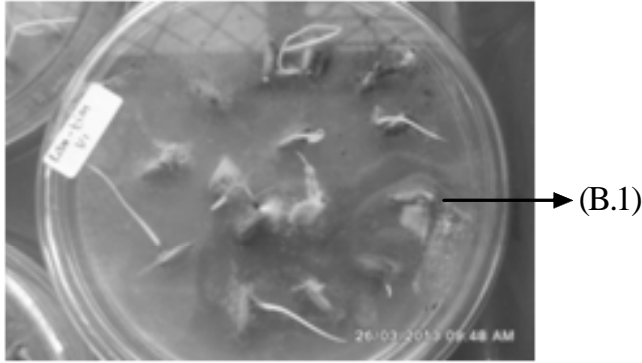

(B)

Gambar 4. Jamur genus Rhizopus. (A) = secara mikroskopis pembesaran $400 \times$, (A.1) sporangiofor, (A.2) sporangium. (B) = secara makroskopis pada benih padi, (B.1) koloni genus Rhizopus berwarna putih.

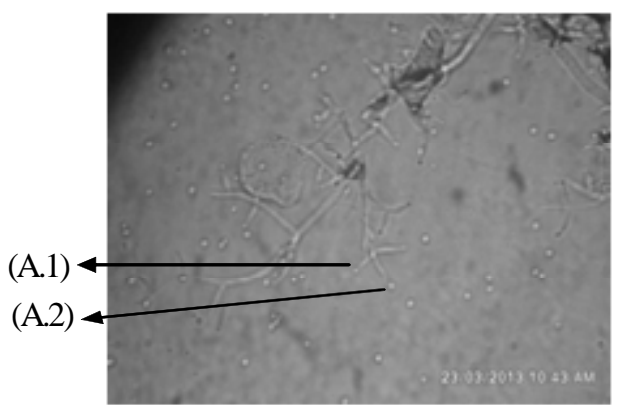

(A)

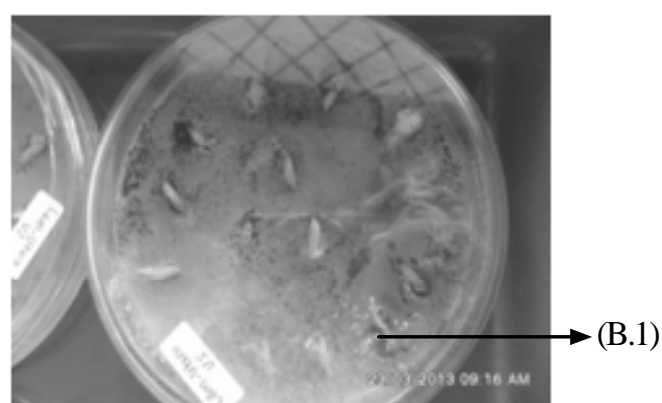

(B)

Gambar 5. Jamur genus Trichoderma. $(\mathrm{A})=$ secara mikroskopis pembesaran $400 \times$, (A.1) fialid, (A.2) spora. (B) = secara makroskopis pada benih padi. (B.1) koloni genus Trichoderma berwarna hijau.

dalam karung tidak disimpan dalam gudang yang khusus melainkan dalam rumah mereka. Keadaan kondisi penyimpanan semacam itu sangat cocok bagi jamur untuk pertumbuhannya karena hangat dan lembab (Neegaard, 1997).

Jamur penyimpanan seperti genus Penicillium dan genus Aspergillus merupakan jamur yang diketahui ada di mana-mana dan hampir terdapat disetiap wilayah. Jamur tersebut biasanya berada diudara dalam jumlah banyak atau mengendap dalam permukaan benda-benda yang terdapat di dalam tempat penyimpanan benih. Selain genus Aspergillus, genus Penicillium, genus Mucor dan genus Rhizopus merupakan jamur penyimpanan karena berada dalam kondisi lembab sehingga potensi pertumbuhannya lebih tinggi. Jamur genus Alternaria, genus Fusarium dan genus Curvularia umumnya menyerang saat panen yang termasuk jamur saprofit dan parasit terbawa yang berada dalam keadaan dorman selama benih disimpan (Justice dan Bass, 1994).

Pada penelitian ini digunakan media PSA (Potato Sucrose Agar) karena media ini sangat cocok untuk pertumbuhan jamur. Genus Aspergillus termasuk dalam kelompok jamur yang berwarna dan cepat tumbuh.
Dengan demikian genus Aspergillus mendominasi jamur-jamur lain yang mampu memanfaatkan nutrisinya sehingga reproduksi dan pertumbuhannya lebih cepat dan juga dipengaruh oleh lingkungan yang diberikan lebih sesuai dengan kehidupan jamur lainnya. Media PSA lebih banyak mengandung nutrisi yang dibutuhkan oleh patogen dalam perkecambahan spora dan jamur sangat memerlukan bahan yang berbentuk zat organik, selain faktor dan keadaan lingkungan tertentu untuk tumbuh dan melangsungkan kehidupannya. Jamur diketahui tidak berklorofil sehingga untuk melangsungkan kehidupannya diperlukan bahan makanan yang telah tersedia. Pada konsentrasi gula yang tinggi dalam substrat yang menghambat bakteri, ternyata beberapa jenis jamur masih mampu tumbuh, demikian pula pada keadaan asam jamur akan lebih tahan pada yang lainnya (Makfoeld, 1993).

\section{KESIMPULAN}

Berdasarkan hasil penelitian maka dapat diambil kesimpulan bahwa jamur yang berasosiasi dengan benih padi yang berasal dari empat kabupaten adalah Aspergillus (37,9 \%), Mucor (33,6 \%), Trichoderma 
(6,3\%), Penicillium (3,9\%) dan Rhizopus (0,6\%). . Jamur yang dominan tumbuh pada benih padi adalah Aspergillus.

\section{DAFTAR PUSTAKA}

Balai Besar Penelitian Tanaman Padi. 2008. Mutu Benih Tanaman Pangan. Balai Besar Penelitian Tanaman Padi. Jawa Barat

Direktorat Jenderal Tanaman Pangan dan Hortikultura. 1999. Pengenalan dan Pengendalian Penyakit Benih. Direktorat Bina Perlindungan Tanaman. Jakarta. $31 \mathrm{hlm}$

Justice, O.L. dan L.N. Bass. 1994. Prinsip dan Praktek Penyimpanan Benih. PT.Raja Grafindo Persada. Jakarta. $446 \mathrm{hlm}$.

Makfoeld, D. 1993. Mikotoksin Pangan. Kanisius. Yogyakarta. $211 \mathrm{hlm}$.
Masniawati. 2013. Identifikasi Cendawan Terbawa pada Benih Padi Lokal Aromatik Pulu Mandoti, Pulu Pinjan, dan Pare Lambau asal Kabupaten Enrekang, Sulawesi Selatan. Masnal. 1(1): 51-59.

Neergard, P. 1997. Seed Pathology. Vol.1. John Wiley \& Sons. New York.

Nurdin, M. 2003. Inventarisasi Beberapa Mikroorganisme Terbawa Benih Padi yang Berasal dari Talang Padang, Kabupaten Tanggamus, Lampung. J. Hama dan Penyakil Tumbuhan Tropika. 3(2): 47-50.

Semangun, H. 1993. Penyakit-Penyakit Tanaman Pangan di Indonesia. Gadjah Mada University Press. Yogyakarta. $449 \mathrm{hlm}$. 